\title{
COLOUR STABILITY, FLEXURAL MODULUS, AND TOUGHNESS OF PMMA DENTURE BASE RESIN MODIFIED WITH SILVER NANO-PAR- TICLES AND HENNA FILLERS
}

\author{
Mostafa I Fayad ${ }^{1 *}$, Gamal Mokhtar Alwafi ${ }^{2}$, Ramy Abdallah Abdelrahim ${ }^{3}$, Ahmed Atef Shon ${ }^{4}$
}

\begin{abstract}
Objective: This study aimed to evaluate the influence of incorporation of silver nano-particles (Ag-NPs) and Henna on colour changes, flexural modulus, and toughness of the heat-polymerized polymethyl methacrylate ( PMMA) denture base material. Materials and Methods: A total of 60 conventional heat-polymerized PMMA acrylic resin samples were fabricated with a conventional compression-moulded technique and used in this study. Modified acrylic resin samples were prepared by addition of Ag-NPs $(0.5$ wt.\%), and Henna fillers ( $1 \mathrm{wt} . \%)$, to the powder of PMMA resin. For colour change evaluation, a total of thirty disc $(20 \times 3 \mathrm{~mm})$ samples $(\mathrm{n}=10$ samples for each type of acrylic resin) were used. While for the transverse strength test, a total of 30 acrylic samples $(65 \times 10 \times 3 \mathrm{~mm})(\mathrm{n}=10$ samples for each type of acrylic resin) . The dimensions of samples were selected according to the American Dental Association (ADA) specifications \#12. Results: The incorporation of Ag-NPs and Henna fillers resulted in significant colour changes in PMMA acrylic resin. At the same time, both added fillers resulted in a significant decrease in the flexural modulus and toughness of the PMMA acrylic resin. Conclusion: Incorporating Ag-NPs and Henna fillers adversely affect the colour of the PMMA and its flexural modulus and toughness.
\end{abstract}

KEYWORDS: Color changes, Acrylic resin, Henna, Denture base, Silver Nano-Particles

\section{INTRODUCTION}

Conventional denture base made up of heatpolymerized acrylic resin material is still the treatment of choice for rehabilitation of complete or partially edentulous patients for financial or medical reasons ${ }^{(1-3)}$. The acrylic resin is considered the preferred material for denture base construction. Its various advantages include good colour-matching ability, biocompatibility, economic coast, and low weight $^{(3-5)}$. However, unfortunately, this material has some inherent shortcomings, which finally cause failure of prosthesis during clinical service ${ }^{(1,3)}$.

Generally, the conventional heat-polymerized polymethyl methacrylate [PMMA] denture base

1. Associate Professor, Department of Substitutive Dental Science, College of Dentistry, Taibah University, Saudi Arabia.

2. Assistant Lecturer of Removable Prosthodontics, Department of Removable Prosthodontics, Faculty of Dentistry, Sert University, Libya

3. Assistant Professor of Dental Biomaterials, Faculty of Dental Medicine, (Cairo, Boys), Al-Azhar University.

4. Assistant Professor of Removable Prosthodontics, Department of Removable Prosthodontics, Faculty of Dental Medicine, Al-Azhar University

•Corresponding author: dr.mifayad@gmail.com

DOI: $10.21608 /$ ajdsm.2021.100560.1255 
material fractured when loaded under flexural or impact strengths that exceeded its flexural or toughness capacity ${ }^{(1,6)}$. The insufficient flexural strength, flexural modulus, and toughness are determinable for the clinical success of the conventional acrylic denture base ${ }^{(7,8)}$. So, various clinical and in vitro attempts were made to overcome these mechanical drawbacks ${ }^{(6,7)}$.

One of these attempts is the reinforcement of the heat-polymerized PMMA via incorporating various fillers as silver nano-particles [Ag-NPs] and Henna fillers ${ }^{(9-12)}$. Ag-NPs have been considered one of the commonest reinforced nanofillers that have been used for prosthodontics due to their extraordinary physical, chemical, and biological properties, including; high electrical and thermal conductivity, chemical stability, and optimal optical properties ${ }^{(9,10)}$. Henna is a natural and renewable medicinal plant used as a skin and hair coloring agent for a hundred years and acts as a rich source of antimicrobial agents, and has a scientific name of Lawsonia Inermis ${ }^{(11,12)}$.

Ag-NPs and Henna have antimicrobial and antiinflammatory effects, so they were used in numerous previous studies with heat-polymerized PMMA to control one of the most common inflammatory conditions that generally accompanied denture wearing and known as denture stomatitis ${ }^{(12,13)}$. Recently, many nano paricles were used as incorporated fillers with heat-polymerized PMMA material to improve the properties of acrylic resin in several previous in-vitro studies ${ }^{(9-12)}$.

The colour stability of the conventional denture is a determinable factor in the prosthesis acceptance by the patient, so the denture colour and translucency should be preserved during the conventional processing and during its strengthening modification $^{(14-16)}$. Acrylic resin is a transparent material, so, during manufacturing, the staining pigments may be added to its powder to give the final prosthesis its colour ${ }^{(15,16)}$. However, the improper powder/liquid ratio could affect its final colour, affecting its other physical properties ${ }^{(15)}$. Moreover, it was found that, to some extent, incorporating Ag-NPs and Henna within the heat-polymerized PMMA resin material may alternate the colour of the acrylic resin material ${ }^{(9,11)}$.

Although the effect of incorporating Ag-NPs and Henna powder as reinforcement fillers have not been sufficiently investigated, limited number of studies are available on the effect of these fillers on the different properties of acrylic resins ${ }^{(9,11,17)}$. Hence, this study was made to evaluate the influence of adding Ag-NPs and Henna fillers on colour, flexural modulus, and toughness of PMMA heatpolymerized acrylic resin.

\section{MATERIALS AND METHODS}

Conventional heat-polymerized PMMA (Vertex $^{\mathrm{tm}}$ Rapid simplified, Vertex Dental Company, Germany), Ag-nano particles $(0.5 \%)$ by weight [Nano-gate Company Egypt], and Henna (1\%) by weight [Local Egyptian industry]; were selected for this study.

\section{Sample Grouping:}

Sixty acrylic samples were used as follow; for the colour change evaluation test, a total of 30-disc samples $(n=10)$ were prepared with dimensions of $(20 \times 3 \mathrm{~mm})$, while, for the transverse strength test, a total of 30 rectangular samples $(n=10)$ were prepared as required by ADA specification \# 12 with sample dimensions of $(65 \times 10 \times 3 \mathrm{~mm})^{(9,18)}$. The samples were divided into three main groups according to additives that incorporated in acrylic resin as follow;

Group 1: unmodified acrylic resin (control group).

Group II: 0.5wt.\% Ag-NPs modified acrylic resin.

Group III: 1wt.\% Henna modified acrylic resin. 


\section{Sample Fabrication:}

Stainless steel metal strips $(20 \times 3 \mathrm{~mm})$ and $(65 \times 10 \times 3 \mathrm{~mm})$ were utilized to evaluate the colour change and transverse strength, respectively. Sixty acrylic resin samples was fabricated; thirty samples for each test $(n=30)$. A modified polymers powders were prepared by addition Ag-NPs and Henna fillers to the powder of PMMA resin with a proportion of 0.5 and $1 \mathrm{wt} . \%$ respectively, using a digital balance (Precisa 205A; Moosmattstrasse, Dietikon, Switzerland), and were agitated with an electric mixer before mixing with the monomer ${ }^{(9,12)}$.

According to the type of test; each stainlesssteel metal strips is painted with a separating medium and then flasked with investment material into a metal flask; after the complete set of investment material, the top half of the metal flask and the stainless-steel strips were removed, leaving spaces in the investment of the bottom half of flask with the same dimension of each stainless-steel metal strips. Then, the mould was painted with a separating medium to apply heat-polymerized acrylic resin of different main groups. Then, the unmodified and modified acrylic resin powders were mixed with monomer liquid according to the manufacturer's instructions (1:1 by volume $)^{(9,12)}$.

Then, the acrylic resins were packed into a specially designed stone mould in the dough stage and flasked. Then, the acrylic resin samples were polymerized through immersion in a temperaturecontrolled curing water bath $\left(73 \pm 1^{\circ} \mathrm{C}\right)$ for about 2 hours. After that, the temperature of water bath was elevated until reach $100^{\circ} \mathrm{C}$. The temperature was kept for an additional 1 hour to complete the polymerization cycle after that, the flask was allowed to cool gradually until it reached room temperature ${ }^{(9)}$. After deflasking, a tungsten carbide bur was used for finishing of the acrylic resin samples, followed by ground with an emery paper120, 200, 400, and 600 grain, respectively, to remove any remaining minor scratches and to get a smooth, highly polished surface ${ }^{(12)}$, (Figure 1).

\section{Testing Procedures:}

\section{1- Color Change Evaluation:}

Thirty acrylic resin discs , $20 \times 3 \mathrm{~mm},(\mathrm{n}=10$ for each type of acrylic resin ) were used in this study for the evaluation of colour change. A spectrophotometer with double beam ultra-violet visible light (U.V-Vis. UV 3101 PC, Shimadzu scanning spectrophotometer) was used for colour changes evaluatution between different acrylic resin samples via assessment of the collected diffuse reflectance data at every $5 \mathrm{~nm}$ of the sample diameter and between the wavelength of $400-700 \mathrm{~nm}^{(14,18)}$.

The colour difference between different group was determined by the following formula: ${ }^{(18)}$

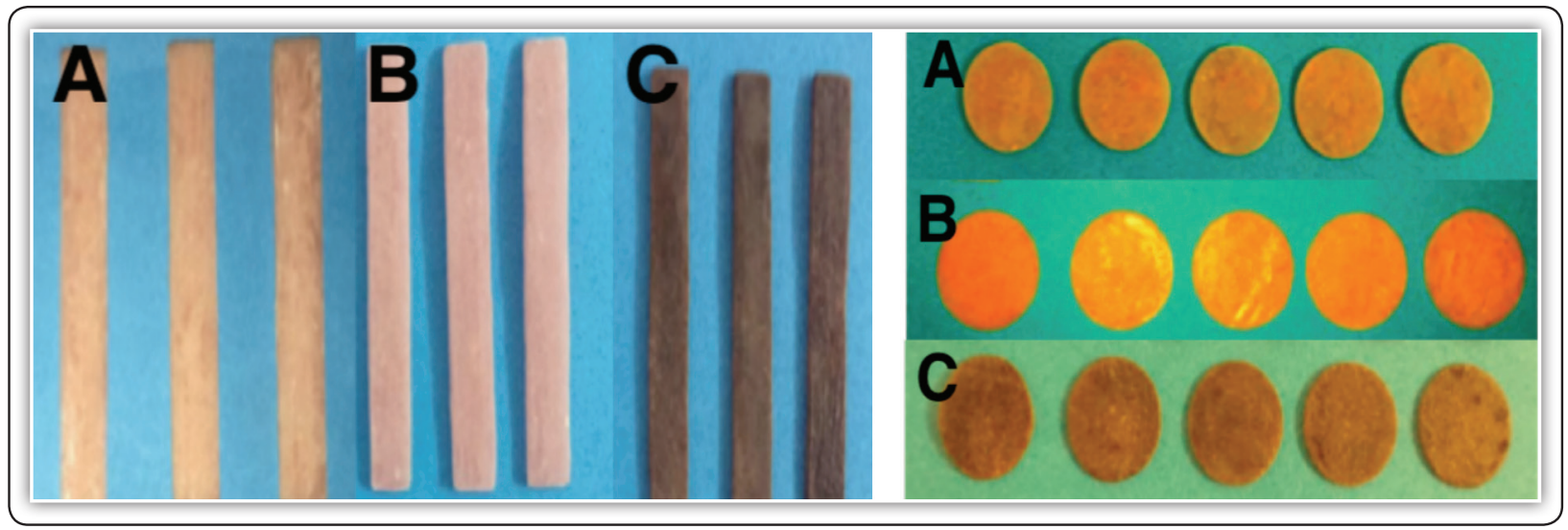

FIG (1) (A); Finished specimens of conventional PMMA acrylic resin, (B); Finished specimens of PMMA modified by $0.5 \mathrm{wt} . \%$ Ag-NPs, and (C); Finished specimens of PMMA modified by 1 wt $\%$ Henna. 
Where: represent the total colour change values: represent the black (0) to white (100) values: represent the green (negative) to red (positive) values, and : represent the blue (negative) to yellow (positive) values.

Then, the resulted colour change values were used to get the National Bureau of Standards (NBS) units, where the NBS values are the colour changes that could be assessed with the human eye. ${ }^{(18)}$.

The NBS values were attained by multiplying the colour change values with 0.92 according to the following equation: ${ }^{(18)}$

\section{2- Transverse Strength Test:}

The flexural modulus and toughness were examined using the transverse strength test. The samples of each tested group $(n=10)$ were prepared with a dimension of $65 \times 10 \times 3 \mathrm{~mm}$ for a three-point bending test (transverse strength test).

Each tested sample was horizontally mounted in a custom-made loading fixture; two parallel stainless-steel metal rods with span length $60 \mathrm{~mm}$ supporting the tested sample on a computer-controlled material testing machine (Model LRX-plus; Lloyd Instruments Ltd., Fareham, UK.) with a load cell of $5 \mathrm{KN}$. The data were recorded using the computer software (Nexygen-MT; Lloyd Instruments). All samples were loaded until fracture at a crosshead speed of $5 \mathrm{~mm} /$ minute $^{(9)}$. The linear slope portion of the stress-strain curve automatically constructed during the testing procedure via the software algorithm was represented for flexural modulus (E) ${ }^{(19)}$. The flexural modulus was calculated via the following equation:

\section{$\mathrm{E}=\mathrm{L}^{3} \mathrm{~m} / 4 \mathrm{bd} \mathrm{d}^{3}$}

Where; E: flexural modulus (GPa); L: span length $(\mathrm{mm}) ; \mathrm{m}$ : the slope of the modulus line $(\mathrm{N} / \mathrm{mm})$, b: width of the specimen $(\mathrm{mm})$; and $\mathrm{d}$ : thicknesses of the specimen (mm).
While the area that represented under the stressstrain curve was indicated for the toughness and it determines the energy in Joules ( $J$ ) that was absorbed by the material until fracture and were calculated and obtained automatically via the soft wear of the testing machine ${ }^{(20)}$.

\section{Statistical Analysis}

The collected data were tabulated and analyzed using SPSS $^{\circledR}$ statistics version 20.0 (IBM, USA). Numerical data were described as mean and standard deviation. Data will be compared using the ANOVA test. At the same time, Tukey's pairwise Post-hoc Test was used to analyze the groups regarding transverse strength test values statistically.

An independent sample t-test was used to statistically analyze the colour change values in each modified group with the control group. Differences were always considered statistically significant at $P$ $\leq 0.05$.

\section{RESULTS}

The colour change results measured as a function of Ag-NPs and Henna modification are summarized in (Table 1). While the results of the studied groups regarding the transverse strength test are shown in (Table 2).

\section{Colour changes:}

\section{Translucency changes $(\Delta L)$ :}

The mean value results of black to white colour changes of the studied samples revealed a higher statistically significant difference. Where, Ag-NPs modified group (group II) recorded the higher translucency change mean value than the Henna modified group (group III) as exhibited by $t$-test $(p=<0.0001<0.05)$. The negative sign means that the modified studied samples became darker than the samples of the control group. 
TABLE (1) Color measurements of the tested samples and NBS units of the colour differences.

\begin{tabular}{|c|c|c|c|c|c|c|}
\hline \multirow{2}{*}{ Variable } & \multirow{2}{*}{$\Delta \mathrm{L}$} & \multirow{2}{*}{$\Delta \mathrm{a}$} & \multirow{2}{*}{$\Delta b$} & Control group & \multirow{2}{*}{$\begin{array}{l}\text { NBS } \\
\text { values }\end{array}$} & \multirow{2}{*}{$\begin{array}{l}\text { Critical remarks on } \\
\text { colour difference }\end{array}$} \\
\hline & & & & Mean \pm SD & & \\
\hline Group II & $-32.46 \pm 1.67$ & $-6.50 \pm 1.86$ & $4.12 \pm 1.01$ & $33.44 \pm 1.44$ & 30.76 & $\begin{array}{l}\text { Change to another } \\
\text { colour }\end{array}$ \\
\hline Group III & $-6.38 \pm 2.89$ & $-8.40 \pm 1.26$ & $5.84 \pm 1.58$ & $12.51 \pm 1.14$ & 11.50 & $\begin{array}{l}\text { Extremely marked } \\
\text { colour change }\end{array}$ \\
\hline$p$-values & $<0.0001 *$ & $0.01 *$ & $0.006^{*}$ & $<0.0001 *$ & & \\
\hline
\end{tabular}

TABLE (2) Flexural modulus (GPa) and Toughness (J) values of the studied groups.

\begin{tabular}{|c|c|c|}
\hline \multirow{2}{*}{ Acrylic samples } & $\begin{array}{c}\text { Flexural modulus } \\
(\mathrm{GPa})\end{array}$ & Toughness (J) \\
\cline { 2 - 3 } & Mean $\pm \mathrm{SD}$ & Mean $\pm \mathrm{SD}$ \\
\hline Group I & $2.905 \pm 0.359^{\mathrm{A}}$ & $0.0861 \pm 0.01^{\mathrm{A}}$ \\
\hline Group II & $2.474 \pm 0.267^{\mathrm{B}}$ & $0.0492 \pm 0.005^{\mathrm{C}}$ \\
\hline Group III & $2.214 \pm 0.266^{\mathrm{B}}$ & $0.0669 \pm 0.009^{\mathrm{B}}$ \\
\hline$P$-values & $<0.0001^{*}$ & $<0.0001^{*}$ \\
\hline
\end{tabular}

\section{Changes of the green-red axis $(\Delta a)$ :}

Regarding green to red colour changes, the samples of the tested groups showed a statistically significant difference. Where, Henna modified the group (group III) exhibited the higher change mean value toward greenish when compared with Ag-NPs modified group (group II) as demonstrated by t-test $(p=0.01<0.05)$. The negative sign revealed that the modified studied samples became greenish than the samples of the control group.

\section{Changes of the blue-yellow axis $(\Delta b)$ :}

The studied samples were exhibited a statistically significant difference regarded to blue to yellowish colour changes. Where, Henna modified the group (group III) recoded the higher change mean value toward yellowish followed by Ag-NPs modified group (group II) as revealed by the t-test $(p=0.006<0.05)$. The positive sign revealed that the modified studied samples became yellowish than the samples of the control group.

\section{Total colour changes $(\Delta E)$ :}

The total colour changes exhibited a higher statistically significant difference, where, Ag-NPs modified group (group II) recorded the higher total colour change $(\Delta \mathrm{E})$ mean value followed by the Henna modified group (group III) as revealed by the $\mathrm{t}$-test $(\mathrm{p}=<0.0001<0.05)$. Regarding NBS values, the colour of the Ag-NPs modified group was changed to another colour. While the colour of the Henna modified group, samples were exhibited an extremely marked colour change.

\section{Flexural modulus:}

The flexural modulus of the studied groups showed a statistically significant difference, where the highest mean flexural modulus value was recorded with unmodified PMMA acrylic resin samples (control group), followed by Ag-NPs modified group (group II) and Henna modified group (group III) respectively. Ag-NPs and Henna modified groups showed no statistically significant difference $(\mathrm{P}>0.05)$ among the tested groups.

\section{Toughness:}

The tested samples of the three studied groups showed a statistically significant difference concerning the toughness. The higher toughness value was revealed with unmodified PMMA acrylic resin samples (control group), followed by Henna modified group (group III). While Ag-NPs modified group (group II) exhibited the lower statistically mean toughness value among the three studied groups. 


\section{DISCUSSION}

The heat-polymerized PMMA acrylic resin powder has a translucent pink colour material. Despite its ease of processing, it has inherited poor mechanical properties, such as poor flexural strength, flexural modulus, and toughness ${ }^{(1-3)}$. To overcome these drawbacks, many types of research were carried out to improve its mechanical properties by incorporating various reinforcing fillers, such as silica, E-glass, nano-particles such as $\mathrm{ZrO}_{2}$, and synthetic polymeric fibers $(5-8,10)$. Recently, various researches attempted to study the influence of antimicrobial agents such as Ag-NPs and Henna on the mechanical and physical properties of the PMMA acrylic denture base material without adversely affecting its aesthetic ${ }^{(2,7,9,12)}$.

The previous studies found that the percentage of the incorporated fillers have a determinable effect on the mechanical reinforcement of the PMMA acrylic resin ${ }^{(9,21)}$. Additionally, the studies carried on AgNPs and Henna fillers as antimicrobial agents when incorporated in acrylic resins revealed that these fillers' minimum antimicrobial inhibitory concentration without significant adverse effect on their mechanical properties was $0.5 \mathrm{wt} . \%, 1 \mathrm{wt} . \%$ for Ag-NPs and Henna, respectively ${ }^{(9,11,12,22,23)}$. Moreover, the previous studies found that the maximum matrix saturation with Ag-NPs and Henna fillers have occurred at these concentrations ${ }^{(9,12)}$. So, in this study, we choose these concentrations as a baseline to evaluate their effect on colour, flexural modulus, and toughness of heat-polymerized PMMA acrylic resin.

A common problem usually seen with the filler reinforcement of the PMMA acrylic resin is colour instability. The colour change of the acrylic prosthesis may compromise aesthetic and finally affect the patient satisfaction and acceptance of the prosthesis ${ }^{(24,25)}$. The colour change was determined by spectrophotometer and could be turned into NBS units to relate its amount and quality to the clinical environment ${ }^{(26,27)}$. NBS parameters are essential for colour comparisons ${ }^{(28)}$. The colour change values
$(\Delta \mathrm{E})$ were turned into NBS values, and their clinical validities were assessed.

The studied groups' colour change values were "very high" in NBS assessments, and they are out of the clinically acceptable limits. As these NBS values, according to the NBS rating system for expressing colour differences were indicate that the Ag-NPs modified group revealed a total change to another colour while the Henna modified group exhibited an "extremely marked change in colour" (18, 29). These colour changes might arise from different types of fillers with different refractive indices in the PMMA materials ${ }^{(30,31)}$.

The decreased translucency of the modified groups was resulted from the different refraction and reflection of light at the filler/matrix interface due to the different refractive indices ${ }^{(31)}$. Furthermore, the increased opacity of the Ag-NPs modified group was due to the higher difference in the refractive index between the filler and resin matrix when compared to the Henna modified group, where the refractive index for Ag-NPs, Henna, and acrylic resin are $(-48.3,1.5036,1.4813)$ respectively ${ }^{(32-34)}$. The change in colour of the Ag-NPs modified group into another colour may be due to the high-negative effectiveness of its refractive index. This is possible because of the negative dispersion of the effective polarizability of the valence electrons in the silver nano-particles ${ }^{(34)}$.

The most common fracture type of the PMMA acrylic denture base is the midline fracture which occurs because of repeated flexure or bending movement during service ${ }^{(9,35)}$. So, the acrylic denture should have sufficient flexural properties to withstand these repeated flexural stresses without fracture ${ }^{(6,9)}$. To evaluate the flexural properties, a bar-shaped sample of tested material is placed on two supports, and a load is applied at the centre (36). This test is known as a three-point bending test "transverse test" ${ }^{35)}$. This test is used essentially to compare and evaluate the new denture base material to determine its suitability to clinical service ${ }^{(37,38)}$. 
It was observed that the flexural modulus and toughness were significantly decreased after the addition of Ag-NPs and Henna powder to the heatpolymerized PMMA acrylic resin. These might attribute to the acting of Ag-NPs and Henna fillers as impurities during the polymerization process that caused a decrease in the degree of polymerization conversion and resulted in more residual unreacted monomers within the matrix act as plasticizer ${ }^{(11,12,}$ ${ }^{38)}$. Additionally, it could be due to agglomeration of these fillers within the matrix, affecting its integrity, distorting its structure, and decreasing its rigidity and flexural properties ${ }^{(9,12)}$.

\section{CONCLUSION}

Incorporating Ag-NPs and Henna fillers adversely affect the colour of the PMMA and its flexural modulus and toughness.

\section{REFERENCES}

1. AlQahtani M, Haralur SB. Influence of different repair acrylic resin and thermocycling on the flexural strength of denture base resin. Medicina. 2020; 56:1-9.

2. Gad MM, Al-Thobity AM, Fouda SM, Näpänkangas R, Raustia A. Flexural and surface properties of PMMA denture base material modified with thymoquinone as an antifungal agent. J Prosthodont. 2020; 29:243-50.

3. Abuelroos IM, Ibrahim TO, Elsisi HA, Makki AZ. The effect of different packing techniques on adaptation of resin denture base materials. Int J Health Sci Res. 2020; 10:28-34.

4. Bacali C, Baldea I, Moldovan M, Carpa R, Olteanu DE, Filip GA, eta al. Flexural strength, biocompatibility, and antimicrobial activity of a polymethyl methacrylate denture resin enhanced with graphene and silver nano-particles. Clin Oral Investig. 2020; 24:2713-25.

5. Raszewski Z, Nowakowska-Toporowska A, Weżgowiec J, Nowakowska D, Więckiewicz W. Influence of silanized silica and silanized feldspar addition on the mechanical behavior of polymethyl methacrylate resin denture teeth. J Prosthet Dent. 2020; 123:647-52.

6. Zidan S, Silikas N, Haider J, Alhotan A, Jahantigh J, Yates J. Evaluation of equivalent flexural strength for complete removable dentures made of zirconia-impregnated PMMA nanocomposites. Materials. 2020; 13: 2580-94.
7. Gad MM, Rahoma A, Abualsaud R, Al-Thobity AM, Akhtar S, Siddiqui IA, et al. influence of artificial aging and $\mathrm{ZrO}_{2}$ nanoparticle-reinforced repair resin on the denture repair strength. J Clin Exp Dent. 2020;12: 354- 62.

8. Prajwala N, Kumar CR, Sujesh M, Rao DC, Pavani L. Denture base reinforcing materials - A review. IP Ann Prosthodont Restor Dent. 2020; 6:52-59.

9. Alla RK, Raghavendra Swamy KN, Vyas R, Konakanchi A, Guduri V, Gadde P. Influence of silver nano-particles incorporation on flexural strength of heat-cure acrylic denture base resin materials. ARRB.2017; 17: 1-8.

10. Vijay A, Prabhu N, Balakrishnan D, Narayan A. Comparative study of the flexural strength of high impact denture base resins reinforced by silver nano-particles and E-glass fibers: An in-vitro study. JCDR. 2018; 12: ZC22-ZC26.

11. Gad MM, Rahoma A, Nawasrah A, Ammar MM. Influence of Henna addition on the flexural strength of acrylic denture base material: an in vitro study. ADJ for Girls. $2018 ; 5: 277-83$.

12. Nawasrah A, Gad M, El-Zayat M. Effect of Henna addition on the surface roughness and hardness of polymethylmethacrylate denture base material: An in-vitro study. Preprints. 2017; 2017040113.

13. Carlos F-A J, Rene G-C, Germán V-S, Susana A-T L. Antimicrobial Poly (methyl methacrylate) with silver nanoparticles for dentistry: A systematic review. Appl. Sci. 2020; 10: 4007-16.

14. Al-Qarni FD, Goodacre CJ, Kattadiyil MT, Baba NZ, Paravina RD. Stainability of acrylic resin materials used in CAD-CAM and conventional complete dentures. J Prosthet Dent. 2020; 123:880-87.

15. Ayaz EA, Ustun S. Effect of staining and denture cleaning on color stability of differently polymerized denture base acrylic resins. Niger J Clin Pract 2020; 23:304-9.

16. Banu F, Jeyapalan K, Anand Kumar V, Modi K. Comparison of color stability between various denture base resins on staining and denture cleansing using commercially available denture cleansers. Cureus. 2020; 12: 6698- 710.

17. Gad MM, Fouda SM. Current perspectives and the future of Candida albicans-associated denture stomatitis treatment. Dent Med Probl. 2020; 57:95-102.

18. Waldemarin RF, Terra PC, Pinto LR, Faot F, Camacho GB. Color change in acrylic resin processed in three ways after immersion in water, cola, coffee, mate, and wine. Acta Odontol Latinoam. 2013; 26:138-43. 
19. Lee H-H, Lee C-J, Asaoka K. Correlation in the mechanical properties of acrylic denture base resins. Dent Mater J. 2012; 31: 157-64.

20. Niem T, Youssef N, Wöstmann B. Energy dissipation capacities of CAD-CAM restorative materials: A comparative evaluation of resilience and toughness. J Prosthet Dent. 2019; 121:101-9.

21. Asopa V, Suresh S, Khandelwal M, Sharma V, Asopa SS, Kaira LS. A comparative evaluation of properties of zirconia reinforced high impact acrylic resin with that of high impact acrylic resin. The Saudi Journal for Dental Research 2015; 6: 146-151.

22. Kassaee MZ, Akhavan A, Sheikh N, Sodagar A. Antibacterial effects of a new dental acrylic resin containing silver nano-particles. J Appl Polym Sci. 2008;110: 1699-703.

23. Nawasrah A, AlNimr A, Ali AA. Antifungal Effect of Henna against Candida albicans Adhered to Acrylic Resin as a Possible Method for Prevention of Denture Stomatitis. Int J Environ Res. Public Health. 2016; 13: 520: 2-8.

24. Sahin Z, Ergun G. The Assessment of Some Physical and Mechanical Properties of PMMA Added Different Forms of Nano-ZrO ${ }_{2}$. J Dent Oral Health. 2017; 3:64-74.

25. Bohra PK, Ganesh PR, Reddy MM, Ebenezar AVR, Sivakumar G. Color stability of heat, and cold cure acrylic resins. J Clin Diagn Res. 2015; 9:5-12.

26. Ergun G, Nagas IC. Color stability of silicone or acrylic denture liners: an in vitro investigation. Eur J Dent. 2007; $1: 144-51$.

27. Tuncdemir A, Aykent F. Effects of fibers on the color change and stability of resin composites after accelerated aging. Dent Mater J. 2012; 31:872-78.

28. Hong G, Murata H, Li Y, Sadamori S, Hamada T. Influence of denture cleansers on the color stability of three types of denture base acrylic resin. J Prosthet Dent. 2009; 101:205-13.

29. Ergun G, Sahin Z, Ataol AS. The effects of adding various ratios of zirconium oxide nano-particles to poly (methyl methacrylate) on physical and mechanical properties. J Oral Sci. 2018; 60: 304-15.

30. Aszrin FN, Takarini V, Hasratiningsih Z, Purwasasmita BS. Translucency evaluation of polymethyl methacrylate (PMMA) reinforced with $\mathrm{ZrO}_{2}-\mathrm{Al}_{2} \mathrm{O}_{3}-\mathrm{SiO}_{2}$ filler system in fabricating indirect restoration. UIP Health Med. 2016; 1:1-7.

31. Nakajima M, Arimoto A, Prasansuttiporn T, Thanatvarakorn O, Foxton RM, Tagami J. Light transmission characteristics of dentine and resin composites with different thickness. J Dent 2012; 40:77-82.

32. Gad M, Abualsaud R, Rahoma A, Al-obity AM, Alabidi $\mathrm{K}$, Akhtar S. Effect of zirconium oxide nano-particles addition on the optical and tensile properties of polymethyl methacrylate denture base material. Int J Nanomedicine. 2018;13: 283-92.

33. Al-Suwaidi A, Ahmed H. Determination of para-phenylenediamine (PPD) in Henna in the United Arab Emirates. Int J Environ Res Public Health. 2010;7(4):1681-93.

34. Altunin KK, Gadomsky ON. High-negative effective refractive index of silver nano-particles system in nanocomposite films. Optics Communicat 2012; 285: 816-20.

35. Ajaj-ALKordy NM, Alsaadi MH. Elastic modulus and flexural strength comparisons of high-impact and traditional denture base acrylic resins. The Saudi Dent J. 2014; 26, 15-18.

36. Ongun S, Kurtulmus S, Meriç G, Ulusoy M. A Comparative Study on the Mechanical Properties of a PolymerInfiltrated Ceramic-Network Material Used for the Fabrication of Hybrid Abutment. Materials (Basel). 2018; 11:1681-95.

37. Choksi R, Mody P. Flexural properties and impact strength of denture base resins reinforced with micronized glass flakes. J Indian Prosthodont Soc. 2016; 16:264-70.

38. Sodagar A, Kassaee MZ, Akhavan A, Javadi N, Arab S, Kharazifard MJ. Effect of silver nano-particles on flexural strength of acrylic resins. J Prosthodont Res. 2012; $56: 120-24$. 